\title{
Novel Textile-Based Solutions of Emergency Shelters: Case Studies and Field Tests of S(P)EEDKITS Project
}

\author{
Alessandra Zanelli, Andrea Campioli, Carol Monticelli, Salvatore Viscuso \\ and Gianluca Giabardo
}

\begin{abstract}
The design of the first aid and reconstruction kits in major disaster scenarios highlights a new frontier for Technology of Architecture and Lightweight construction expertise, combining the traditional vocation of component design with innovative research on technical textiles. After an overview of S(P)EEDKITS-a project which received funding from the EU FP7 - the essay focuses on research activities conducted by the ABC Department at Politecnico di Milano on the sustainable design applied to textile-based shelters. The essay also presents the results of two field tests conducted in Burkina Faso (2013-2014) and in Senegal (2015on going), evaluating the environmental performances of shelters developed by the authors. The research was conducted in collaboration with International Federation of Red Cross and Red Crescent Societies, Netherlands Red Cross, the Médecins sans Frontieres (Operational centre of Amsterdam),- -Operational centre of Amsterdam, Sioen Industries NV, Ferrino SpA, and with researchers of Vrije Universiteit of Brussel and Eindhoven Technische Universiteit.
\end{abstract}

Keywords Emergency $\cdot$ Shelter design $\cdot$ Packaging design $\cdot$ Textile architecture $\cdot$ Lightweight construction $\cdot$ Product development $\cdot$ Adaptability

\section{Introduction}

"S(P)EEDKITS: rapid deployable kits as seed for self-recovery" has been a collaborative project granted from the EU 7th Framework Programme; the call to which the project responded dealed with the rapid deployment of shelters, facilities and medical resources after a disaster. As specified by the title of this project, the objective was the development of novel emergency solutions, able to speed-up the response of humanitarian organisations (NGOs) during the first days after the disaster. Solutions

\footnotetext{
A. Zanelli · A. Campioli · C. Monticelli · S. Viscuso ( $\varangle)$

Architecture, Built Environment and Construction Engineering-ABC Department, Politecnico di Milano, Milan, Italy

e-mail: salvatore.viscuso@polimi.it

G. Giabardo

Department of Design, Aalto University School of Arts, Design and Architecture, Espoo, Finland

(C) The Author(s) 2020

N. Aste et al. (eds.), Innovative Models for Sustainable Development in Emerging African

Countries, Research for Development, https://doi.org/10.1007/978-3-030-33323-2_10
} 
needed to be clever and durable enough so that the affected population can (re)use them during the reconstruction phase. This dual approach-"speed" and "seed"was crucial as the recent trend in emergency aid for NGOs is to stimulate as early as possible the affected population.

The S(P)EEDKITS project aimed to scrutinize the current used materials and equipment of the organization's Emergency Response Units (ERUs), and to develop novel solutions which drastically reduce their deployment time, the volume and weight for transportation. Normally, NGOs have sleeping ERUs in strategic worldwide warehouses, in order to deliver them immediately after the disaster strikes. Each ERU has specific modules (e.g. sheltering, sanitation, medical care, drinking water supply, basic energy needs) that can be used according to the assessment of the needs and that is intended for a specific number of people. Thus, the purpose of S(P)EEDKITS was to create new ERUs modules/kits that can contribute to saving the lives of people in the first days while planting the seeds for rebuilding future. One strategic key-point of this project was the use of technical textiles and lightweight construction to re-design and re-engineer current shelters and facilities of the emergency sector, thus developing more innovative solution that were easy to be handled, provided and transported.

The European Research Council (ERC) interest on the lightweight textile structures has been clearly evinced by the sub-topic of "lightweight construction, textile technology" under the "PE8: Products and process engineering" strategic research sector. That topic has been encouraging research and experimentation of new building solutions that go beyond the current accepted practices and standard applications of traditional materials to achieve both energy efficiency and structural stability through new lightweight materials, in particular technical textiles.

To reach these ambitious goals, the $\mathrm{S}(\mathrm{P})$ EEDKITS project team consisted of carefully selected partners, organized in workpackages (WPs). It was coordinated by the Belgian textile research centre (CentexBel) and also guided by the operational humanitarian actors like the International Federation of Red Cross and Red Crescent Societies (IFRC), the Netherlands Red Cross (NRC), the Médecins sans Frontières (Operational centre of Amsterdam) and the Norwegian Refugee Council (NRC).

The research activities were also supported by humanitarian research entities like Waste, Practica Foundation and the Internationales Biogas und Bioenergie Kompetenzzentrum (IBBK), while further key partners-like Milson B.V., De Mobiele Fabriek B.V., D'Appolonia SpA, Ferrino SpA and Sioen Industries NV shared their industrial expertise.

Furthermore, three academic partners were also involved-the Vrije Universiteit of Brussel (VUB), the Technische Universiteit of Eindhoven (TUE) and the Politecnico di Milano (POLIMI). They contributed their knowledge in the designing of new shelters, testing their performances through experimental field activities and optimizing their packaging and logistic aspects, with respective focuses on structural engineering (VUB), building physics (TUE), industrial design and architecture (POLIMI). 


\section{Research Methodology}

Following a comparative analysis of terminology in different organizations - such as the European Commission's Civil Protection and Humanitarian Aid Operations (ECHO), the United Nations Office for the Coordination of Humanitarian Affairs (OCHA) and the International Federation of Red Cross and Red Crescent Societies (IFRC) - partners indentified the following common phases in the emergency management: emergency phase (first $48 \mathrm{~h}<$ time), relief $(48 \mathrm{~h}<$ time $<2 / 4$ weeks), recovery and development (time $>2 / 4$ weeks). Before approaching the design of new kits dealing both with "speed" (in terms of transport/installation) and with "seed" (in the reconstruction phase subsequent to the emergency), it was important to investigate concepts of "kit" and "systemic design" in the traditional building process.

According to the Construction Products Directive-89/106/EEC, a "design system" can give rise to one or more kits, each of which may have different combinations of components. Following CPD directive (Fig. 1a), a construction product is a kit when it is a set of at least two separate components that need to be put together to be installed permanently (i.e. to become an "assembled system"). There are two possible types of kit those in which the number and type of components are pre-defined and remain constant and those in which the number, the type and the arrangement of components change according to a specific application. Some kits may be made up of one of many different possible combinations of components from a "design system" depending on the building in which it will be installed. Harmonized specifications shall cover kits in which the number and type of components are pre-defined and remain constant. They shall also cover an entire "design system", i.e. kits where the number, the type and the arrangement of components change according to a specific application.

In that sense, the $\mathrm{S}(\mathrm{P})$ EEDKITS design process was conceived as a "systemic design" on which all ERU kits are developed (Fig. 1b). The re-usability of some components of the kits was thus the peculiarity of this research approach, which aimed to create durable kits and reusable parts; each new kit can be different and customized,
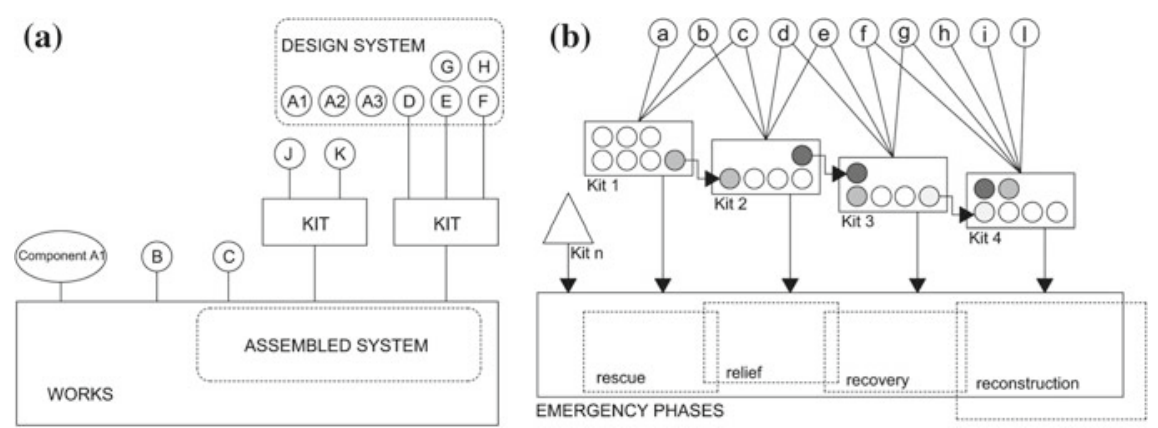

Fig. 1 a Relation between "Design System" and "Kit" in the building sector (construction products directive-89/106/EEC), b S(P)EEDKITS system design and the seed concept 
targeted for a specific emergency phase, but with the following common peculiarities: (i) design system allows different combination of components in custom kits (for different climatic contexts; different cultures; means od transportation); (ii) some components can be reused in the subsequent emergency phases as a component of the forthcoming kit, which are later delivered; (iii) components should be ready from the very beginning relief phases but should later became useful building elements during the reconstruction phases.

As leader of "WP1-Modularity and packaging" and strategic partner of "WP2 Shelters", the role of POLIMI was mainly to find those "design harmonized specifications" which can be considered as a constant for many kits, in order to support each partner in systemizing relations between the different components of a kit to methodically plan the multiplicity of their "assembled system" which they should foresee to deliver in several emergency, climatic and cultural contexts and throughout different response phases.

The complexity of this research approach arised from the fact that a design system itself is made up of multiple nodes with multiple sub-nodes/sub-systems, with variable integration levels and transversal compatibilities among the nodes of this system. Even referring to Meadows (2008), designing a system (of systems) is about defining the relations between the different parts in an artifact within a boundary. The challenge for the POLIMI team was to determine those special emergent properties that make the kits developed in the whole project reciprocally harmonious and understandable for all users throughout the emergency process. Properties considered as emerging are listed below: (i) resilience, the ability to be robust and long lasting throughout different loops of uses; (ii) self-organization, that is the capability to self transforming starting from a modular scheme to a more complex shape; (iii) hierarchy of the whole system, the associative rules based on a bottom-up evolutionary approach. More specifically, requirements followed in the development of new shelter concepts and packaging framework were dealing with the concepts of lightness, ease of transport, low price, simplicity, modularity, ergonomics, reliability, robustness, durability and multiplicity.

\section{Packaging Design}

At the beginning of the research activities of "WP1-Modularity and packaging", the POLIMI team explored and evaluated several commercialized packaging solutions that through a transformation can change their shape, volume or function. The state of the art (SOTA) mapped some interesting solutions, organized into two crossmatrixes: forms/materials and transformational dynamics/materials. The first map considered different shapes and lays them out on a matrix with various materials usually adopted in packaging solutions; the second one outlined different dynamics that can happen within the packaging itself to have it change its shape, function or volume (Zanelli et al. 2014). 
(a)
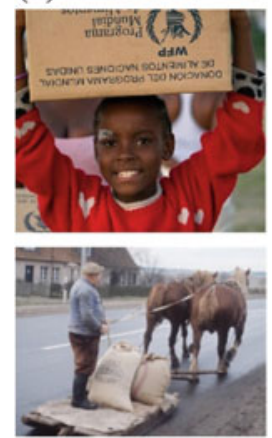
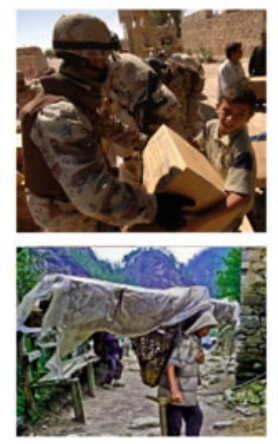

(b)
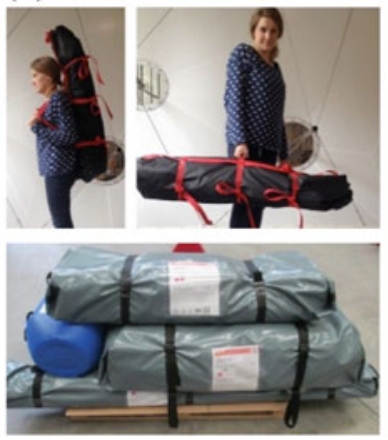

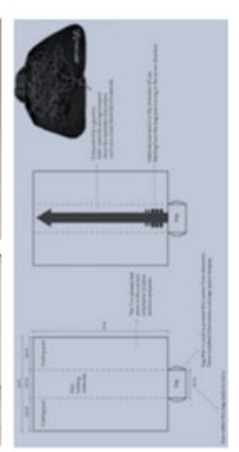

Fig. 2 a Current packaging in emergency field, b S(P)EEDKITS basic bag concept

In order to list profitable examples and inspiring solutions that can be transfer from other sectors to the emergency field, special attention was done to the following design principles, thus qualifying the state of art as a systemic catalogue of multipurpose concepts: (i) the rhizomes as system of systems; (ii) the nesting as an optimizing process; (iii) the identity and information layer; (iv) the handling as the key strategy for new smart packs made of textiles. Taking into account these design principles, POLIMI worked on a novel packaging concept ("basic bag"), used for WP2 shelter kits, and on the optimization strategies that all the partner-involved in the consortium as kit developers-needed to apply. Strategies were targeted at maximizing occupation, managing modular composition of items in the load, reducing voids and minimizing handling (Fig. 2).

The developed "S(P)EEDKITS basic bag", considered as a pilot concept design, is flexible enough to become the founding element upon which it is possible to develop the modular, rhizomatic system. The basic bag concept consists in a module made of durable technical textiles, produced in two diverse sizes derived from a subset of the Euro-pallet (length $=120 \mathrm{~cm}$; width $=80 \mathrm{~cm}$ ). Through a cyclical replication of the sizes, it is possible to obtain a maximum of six combinations that satisfy all the dimensioning variations expected in S(P)EEDKITS. Referring to the bag material, the research focused on layered HDPE/Kraft Paper, non-woven textiles, PP and PE woven textiles. The final design also included material labelling with information of further potential uses for the end of life/recycling.

\subsection{The Rhizomatic Concept}

In 1983 the philosopher Gilles Deleuze and the psychoanalyst Félix Guattari used the term "rhizome" and "rhizomatic" to describe theory and research that allows for multiple, non-hierarchical entry and exit points in data representation and interpretation. 
In "A Thousand Plateaus" they opposed it to an arborescent conception of knowledge, which works with dualist categories and binary choices. A rhizome works with planar and trans-species connections, while an arborescent model works with vertical and linear connections (Deleuze and Guattari 2004). Transferring this theory into the packaging design, POLIMI team noted divers suggestions of on-market products in which all packed elements were horizontally compatible in terms of stacking, loading, transporting and assembling. After analysed this peculiarity in SOTA, the ideal output in S(P)EEDKITS was a coherent and homogenous family of packaging that can always interact with each other at different levels: size-compatible, volumeoptimized, modular, light, easy to handle, easy to recognize, understandable in terms of communication and instructions, compatible in terms of identity.

\subsection{The Nesting Concept}

In packaging design, the nesting concept approaches the issue of optimizing volume occupation and weight, possibly generating modular elements that can work on any level, from the bag/box to the pallet and the container levels. The development of a nesting approach was the core of the POLIMI research activity on WP1, focused on making the process of packaging and the logistic chain simpler. A relevant part was the dimension/quantity constraints of the basic element or component at the bag level, that can reproduce itself or multiplicate and be accommodated in the pallet/container level.

\subsection{The Visual Identity Concept}

The identity concept deals with the way packaging and its content are identified and identifiable. This area of the project intervenes on a layered set of instances, from the system identity on a "brand" level to the functional one. In S(P)EEDKITS, the goal of the identity concept was thus to integrate an "across the board" tagging/labelling/information/instruction/branding communication system for the whole research project. A specific research into the colour coding and branding was conducted with the NGOs_-involved into the research project—-that are active in the field (namely IFRC, NLRC, NRC). Furthermore, a visit was organized to the German Red Cross (GRC) Logistic Centre in Berlin to further explore and experience the matter of packaging, stock management, logistic and markings. POLIMI studied the way GRC labels their equipment. They use a mixed colour/text labelling that refers to a coding system that is well known within the organization but that might, however, not work so well with "outsiders" who are not familiar with the markings and abbreviations. Starting from those assumptions, the POLIMI team worked on the 
development of a layered system, where S(P)EEDKITS identity is clearly communicated and always present together with all the contents related to tagging-labellinginformation-instruction, while keeping an open possibility for customization for the acquiring organization. The research team also explored ways to render accessible the colour code to people suffering from colour blindness.

\subsection{Handling as the Key Strategy}

As S(P)EEDKITS was focused on lightweight solution easy to transport, partners were induced to develop several bag-based kits, like the shelters of the WP2, with a keen eye on the resistance, durability and protectiveness of the packaging. To optimize bag/box useability (third packaging level) POLIMI analysed different ways of human-handling the objects. This task was strongly linked to habits, cultures and traditions and their differences. The three main ways that were mapped are: (i) lifting; (ii) rolling/sledging; (iii) transporting on-body (head, shoulders etc.). This overview gave a panorama of the different conditions of packaging that the POLIMI team followed in order to find easy ways of handling and transporting the kits while minimizing the inherent risks connected to the transport and use.

\section{Shelter Design}

In humanitarian field, shelter products are mainly developed as "closed" prefab systems that work independently to other provided shelters and local materials. Prefabricated designs are developed ad hoc and their parts often require timeconsuming assembling. Sometimes prefab products do not include instructions for post-emergency use or disposal. As result, abandoned temporary shelters become common, sad reminders of the easy waste of money and resources. Moreover, the different climatic contexts require from NGOs a huge faculty of adaptation as each situation calls for a precise answer. Recent emergencies draw attention to limits of current standard tent to be adapted in all climates or in places with high dailytemperature ranges (Aquilino 2011).

For overcoming this critical aspect of current shelter kits, the development of novel solutions aimed to offer an effective winterized solution that also well works in warm and hot climates. The idea of a progressive solution was adopted according to local constraints: it was not only linked to climate risk, but also dependent by local resources (Virgo et al. 2014). Adaptability was to ensure both a prompt firsttime repair, that can be easily erected, and an effective protection in a medium and long-term period, so configuring the "core" of a transitional dwelling.

Moreover, a novel shelter system should not only link to climate risks and local resources, but also relate to cultural identity of the affected population. The novel 
shelter kit has to be inserted in an affected area (urban area, improvised camp, rural region etc.) to reach as quickly as possible an acceptable post-disaster situation towards the rebuilding of economic and social life. By providing shelter kits that are adaptable to users' practices (tribal composition, lifestyle, religious claims, etc.), the rescue could be organized with a people-centred approach in which refugees enclose themselves private spaces, even inside damaged buildings. This feature can improve the acceptance level of the entire sheltering process during a disaster.

The concept generation aimed to transfer the practical users' needs in a set of shelter concepts. In extreme climate conditions, the first basic need is to protect the displaced population against external agents. On these fields, the lack of insulation of standard tents and damaged building is more critical than the request of structural elements (timber or steel) and blocks, which are easily recoverable from local markets. Thus, potential novel shelters should mainly provide flexible panelling systems to adequately winterize beneficiaries; they might be compatible with standard tent structures and locally available structures (frames, simple poles, trees, etc.); finally, they could be adaptable to diverse functions depending on needs (e.g. the roofs after a hurricane, floors during flooding, etc.).

Requirements and inputs coming from S(P)EEDKITS partners (IFRC, SIOEN and CENTEXBEL) were translated in a list of metrics. The list reflected as directly as possible the degree that new concepts had to approximate for satisfying emergency needs and production skills. As sketched in Fig. 4, in product design, the workflow usually starts establishing a set of specifications, which spells out in precise, measurable detail what the product has to do (Ulrich and Eppinger 2011).

\subsection{Textile Wall}

The first concept developed by POLIMI referred to a tri-dimensional cell panel (named "textile wall") that can deliver on roll and configure diverse layout on the field. By using the roll panels to enclose a living space, one or more tarpaulins can cover wall layouts, while the poles used to tension roof membrane also stiffen the corners of panel. After an initial use as simple membrane partitions (with cell empty or partially filled for ballasting the base), panels can be gradually stuffed or used as formworks for concrete. For this aim, it could encourage local users to reuse panels to repair or rebuild homes, taking into account own constructive and social background. Panels should also work to construct raised basement or to cover flat or pitched roof, with cells used like air cavities or insulated (Zanelli and Viscuso 2015).

On October 2013, SIOEN fabricated 12 m-length prototype of textile wall with thickness of $20 \mathrm{~cm}$ and height of $150 \mathrm{~cm}$. The roll was shipped in the refugee camp of Sanioniogo (Burkina Faso). From the 3rd to the 10th November, IFRC and POLIMI set-up the wall under a tensioned roof (developed by VUB University of Bruxelles), with the support of Lux Red Cross and Burkina Red Cross (Fig. 3). In that case, due to the dry environment (and soil) it was not possible either to prepare trenches 

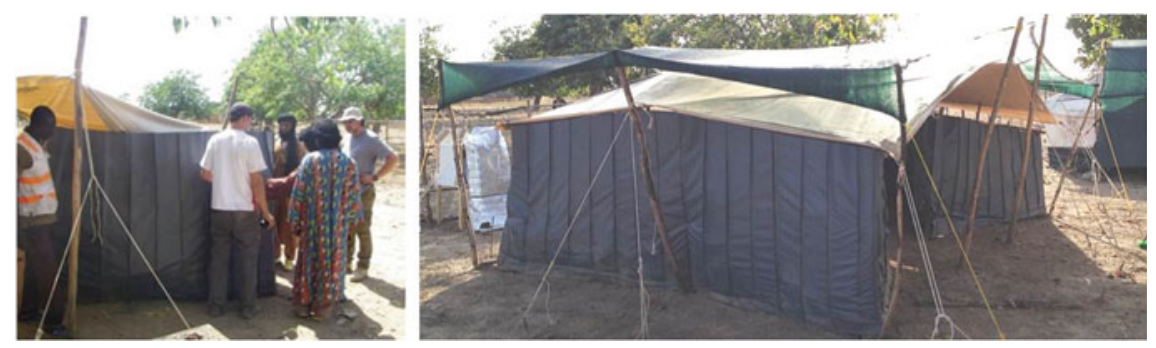

Fig. 3 S(P)EEDKITS field test in Sanioniogo, Burkina Faso, November 2013

or to collect a large amount of filling material. Therefore, it was not possible to fill the panel without inserting structural elements into its small cells. After positioning the Textile wall along a covered area of $15 \mathrm{~m}^{2}$, locally available dried eucalyptus poles were used to prepare two frames made with horizontal and vertical elements crossing each other every $1 \mathrm{~m}$ approx. Connections were fixed with ropes. This first prototype erected in Sanioniogo has been shown during the MILIPOL, the annual exhibition about safety and risks, held in Paris from 17th to 20th November 2013, achieving a good evaluation from NGOs and field operators.

\subsection{Cocoon}

The second concept consisted in a complete living accommodation (dimensioned on module of $3.60 \times 1.80 \mathrm{~m}$ ), that can fix to whatever structural element by means of polyester belts. It allows crating a confined, winterized space to assure intimacy and protection. The amount of material needed oriented towards a lightweight insulating material, such as a non-woven polyester fabric with thickness of $20 \mathrm{~mm}$.

On December 2015, partners shipped 10 cocoons to Senegal for a field test in Ntiagar, a village close to Dakar that is inhabited by Ronkh community (Fig. 4).
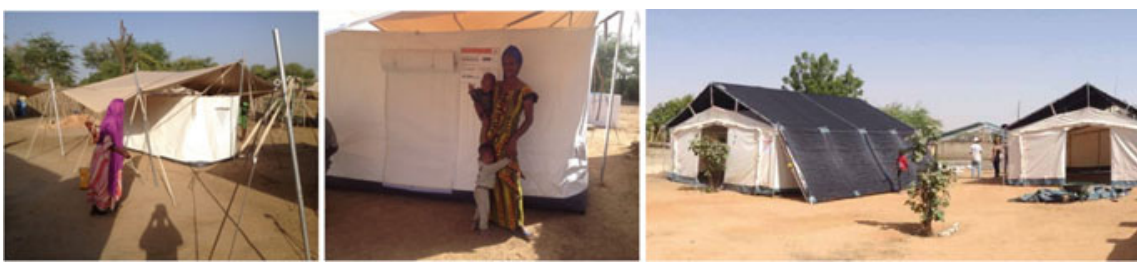

Fig. 4 S(P)EEDKITS field test in Ntiagar, Senegal, December 2015 
Taking into account packaging guidelines developed within the WP1 modules were wrapped with thermoplastic film in a kit including eight polyester belts provided with tensioners, four pegs and the instruction manual. Once arrived on site, the weight of the whole bale (30 kg approx.) allowed a carry-on local transport (1 person per bag). The Luxemburg Red Cross used the modules together with poles provided within the tensioned roof developed by VUB. Products were observed during a three-month's period, characterized by low temperatures (that sometimes lowered to $12 / 12{ }^{\circ} \mathrm{C}$ during the night) and very strong winds (Harmattan winds) with forces often superior to $60 \mathrm{~km} / \mathrm{h}$ and heavily charged with dust. This represented an important test element since the illnesses due to dust and wind in the winter Saharan season are widespread.

\subsection{Multipurpose Tent}

The multipurpose tent is an emergency shelter designed for hosting collective activities and functions that need bigger use surfaces (accommodations, medical room, meeting room, etc.). For that reason, particular attention was given to the usability of the inside space (e.g. vertical walls instead to inclined sides) that increase the net internal area and facilitate the connections between units (both on the front and along the sides), allowing the creation of bigger spaces and camp infrastructures. A single unit measures $48 \mathrm{~m}^{2}$ and was designed to host between 10 and 12 people. All the connectors are the same but rotated, in order to facilitate the set-up in emergency contexts. They functions also as shade net antennas, allowing the elimination of additional framework, the shade net can be integrated in the basic kit. The fabric layer is composed by a breathable material (polycotton) for the upper part and a waterproof groundsheet (not separated) for the bottom layer; it is hanged from inside the structure in order to ease the assembling. Although the tent has a net internal area of $48 \mathrm{~m}^{2}$, the structural design is compliant with snow and wind load specifications of UNI EN 13782:2015 (Temporary structures. Tents. Safety), that describes safety requirements which need to be observed at design, calculation, manufacture, installation, maintenance, of mobile, temporary installed tents with more than $50 \mathrm{~m}^{2}$ ground area. S(P)EEDKITS partners observed functionality and reliability of two multipurpose tents during the test in Ntiagar (December 2015). During the test, NGOs and local people verified that the mounting is simple and intuitive, also because it can be set-up without the need of special tools (Fig. 4). 


\section{Conclusion}

This contribution is intended to describe the design of novel packaging principles and shelter components that contrasts the global production of emergency items through a "glocal" approach. This feature may change the current, local perception of sheltering provision because it links prefab production and its standardized transportation with local markets and relative construction technologies, favouring the acceptance from beneficiaries (Charlesworth and Ahmed 2012). Within the S(P)EEDKITS project, the collaboration with NGOs and manufacturers allowed to include in the design process both the real needs on the field and the current technologies in sheltering production. Metrics coming from requirements permitted a selection between diverse design concepts; finally, the most effective one was prototyped and tested on the field.

Referring to POLIMI research outcomes, both packaging principles and shelter design achieved good evaluations from humanitarian operators that highlighted how the mounting is very simple and intuitive. In any field test organized within the dissemination activities of S(P)EEDKITS, after a quick demonstration of the mounting, local people were able to perform the mounting by themselves, without making mistakes. After two years from the field test in Senegal, shelters are still used by beneficiaries: they are in the same state as they were when mounted, without any sign of deterioration. Users also observed that the shelters are cleanable and maintainable in a good state. Internal temperatures are acceptable thanks to the shade nets during the day and the insulation has allowed maintaining a good temperature during the night. Moreover, mosquito net layers avoid the entrance of sand or dust inside the shelter notwithstanding Harmattan winds.

\section{References}

Aquilino MJ (2011) Beyond shelter: architecture and human dignity. Metropolis Book, New York Charlesworth E, Ahmed I (2012) Shelter and disaster risk reduction in the Asia-Pacific region: final report. Humanitarian Architecture Research Bureau (HARB), RMIT University, Melbourne

Deleuze G, Guattari F (2004) A thousand plateaus: capitalism and schizophrenia. University of Minnesota Press, Minneapolis

Meadows DH (2008) Thinking in systems: a primer. Chelsea Green Publishing, White River Junction, VT

Ulrich K, Eppinger D (2011) Product design and development, 5th edn. McGraw Hill/Irwin, New York

Virgo V, De Vilder I, Viscuso S, Roekens J (2014) Field study Burkina Faso, S(P)EEDKITS WP2 report, 27 Jan 2014

Zanelli A, Viscuso S (2015) Flexible panel-Pannello flessibile. Application numbers: WO2016166658A1. Assignee: Politecnico di Milano

Zanelli A, Buyle G, Giabardo G, Viscuso S (2014) S(P)EEDKITS \& smart packaging. Nuove applicazioni tessili per ridefinire la risposta alle emergenze. TECHNE, vol 8 
Open Access This chapter is licensed under the terms of the Creative Commons Attribution 4.0 International License (http://creativecommons.org/licenses/by/4.0/), which permits use, sharing, adaptation, distribution and reproduction in any medium or format, as long as you give appropriate credit to the original author(s) and the source, provide a link to the Creative Commons license and indicate if changes were made.

The images or other third party material in this chapter are included in the chapter's Creative Commons license, unless indicated otherwise in a credit line to the material. If material is not included in the chapter's Creative Commons license and your intended use is not permitted by statutory regulation or exceeds the permitted use, you will need to obtain permission directly from the copyright holder.

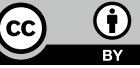

